\title{
Numerical and Experimental Research on Cold Compression Deformation Method for Reducing Quenching Residual Stress of 7A85 Aluminum Alloy Thick Block Forging
}

\author{
Cui Jin-dong, Yi You-ping, and Luo Guo-yun \\ School of Materials Science and Engineering, Central South University, Changsha 410083, China \\ Correspondence should be addressed to Yi You-ping; yyp@mail.csu.ed.cn
}

Received 24 May 2016; Revised 31 July 2016; Accepted 8 March 2017; Published 19 March 2017

Academic Editor: Sutasn Thipprakmas

Copyright (c) 2017 Cui Jin-dong et al. This is an open access article distributed under the Creative Commons Attribution License, which permits unrestricted use, distribution, and reproduction in any medium, provided the original work is properly cited.

In aeronautical machining industry, the most difficult problem to deal with is the distortion of aviation integral component, one main cause of which is the existence of quenching residual stress of forgings, especially for large-sized ones. Therefore, it is important to study the methods that can reduce the quenching residual stress. In this work, the distribution of quenching residual stress of 7A85 aluminum alloy thick block forging, as well as the effect of cold compression deformation method on reducing quenching residual stress, has been investigated by simulation. The results show that, in length direction of 7A85 aluminum alloy thick block with a large size of $260(H) \times 1150(W) \times 5300(L) \mathrm{mm}$, quenching residual stress can be significantly reduced by about $2.5 \%$ cold compression deformation along the direction of highness, with residual stress in length direction ranging from -65 MPa to $60 \mathrm{MPa}$, compared with its counterpart after quenching from -170 MPa to $140 \mathrm{MPa}$. Then a cold compression experiment was carried out, in which the forging residual stress on the surface was measured by X-ray diffraction device. The experimental results indicate that the optimal compression deformation value is $1 \%-2 \%$, reducing $70 \%$ residual stress for 7 A 85 aluminum alloy specimens in size of $100(L) \times 60(W) \times 40(H) \mathrm{mm}$.

\section{Introduction}

Aluminum alloys are the primary material for structural components of military aircrafts, helicopters, amphibious warships, and so forth for several decades. This is because of the low specific gravity of aluminum which favors the selection of aluminum alloys in weight-critical applications [1]. 7A85 aluminum alloy developed in China in recent years is a new type of high-strength aluminum alloys, whose performance is similar to 7085 aluminum alloy that has been developed by Alcoa company since 2002. In order to gain high-strength performance, a series of heat treatment processes must be carried out including a severe quenching operation which introduces a very high level of residual stress in these aluminum alloys forgings. Quenching residual stress not only results in unexpected machining distortion, but also increases the possibility of unpredicted fatigue failures and stress corrosion cracks (SCC) $[2,3]$. Therefore, it is of great significance to investigate quenching residual stress prediction and reduction methods in aircraft aluminum parts.

A lot of research on quenching residual stress has been carried out by researchers. Particularly with development of computer technology in recent years, numerical simulation technology has become an effective way to simulate the generation and distribution of residual stress during quenching process. Koç et al. used the finite element method to simulate the quenching and prestretching process to predict residual stress value of quenched and prestretched aluminum blocks [4-6]. Wu et al. studied the residual stress in aluminum blocks with different quenching processes [7-9]. Prime and Hill used the crack compliance method to measure the residual stress value in products of Alcoa and obtained residual stress distribution of quenched aluminum block and the corresponding prestretched block [10, 11]. Muammer et al. studied the residual stresses in quenched aluminum blocks 


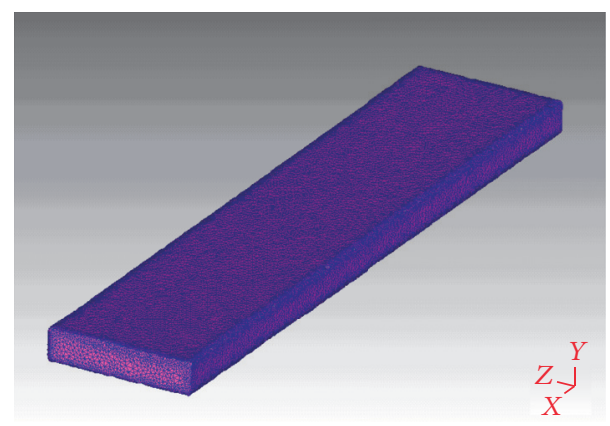

FIgURE 1: Finite element model.

TABLE 1: Heat transfer coefficient of 7A85 aluminum alloy.

\begin{tabular}{lrrrrrr}
\hline Temperature $\left({ }^{\circ} \mathrm{C}\right)$ & 20 & 100 & 200 & 300 & 400 & 500 \\
\hline $\begin{array}{l}\text { Transfer coefficient } \\
\left(\mathrm{W} / \mathrm{m}^{2} \cdot \mathrm{C}\right)\end{array}$ & 2500 & 5000 & 13857 & 10000 & 3000 & 700 \\
\hline
\end{tabular}

and their reduction through cold working processes $[12,13]$. In this work, the effect of cold compression deformation on reducing quenching residual stress was studied through numerical simulation and experiment.

\section{Simulation}

2.1. Finite Element Model and Simulation Parameters. A thick block forging of 7A85 aluminum alloy with a large size of $260(H) \times 1150(W) \times 5300(L) \mathrm{mm}$ was chosen as the test component for the numerical analysis. The quenching and cold compression processes were subjected to numerical simulation in this study. The block was quenched in water of $20^{\circ} \mathrm{C}$ from initial $470^{\circ} \mathrm{C}$ and then $1 \%-5 \%$ cold compression deformation was conducted on the block along the highness direction. Finite Element Code Deform-3D was used to simulate the two processes. The shape and finite element model are shown in Figure 1.

Heat transfer coefficient between 7A85 aluminum alloy block and water which is the most important parameter in quenching process is given in Table 1 [14]. The heat capacity of 7A85 aluminum alloy obtained through DSC method by using the instrument NETZSCH STA 449 C is shown in Table 2. Flash method was used to get the thermal conductivity coefficient of 7A85 aluminum alloy by JR-3 machine. The measurement of thermal expansion coefficient was completed through NETZSCH DIL402C device. Both of them are given in Table 2.

2.2. Quenching Simulation Results and Discussion. Figure 2 shows the simulated results of temperature profile for the cooling time $10 \mathrm{~s}$. Obviously, the temperature of edge at the block is the lowest and the temperature difference between the edge and the highest temperature of the block is about $400^{\circ} \mathrm{C}$. This is due severely to heat convection at the edge along any two axis directions. The temperature gradient and temperature difference gradually decrease with prolonging cooling time. Two characteristic points 1 (surface) and 2
TABLE 2: Thermal conductivity and thermal expansion coefficient of 7A85 aluminum alloy.

\begin{tabular}{lrrrrrr}
\hline Temperature $\left({ }^{\circ} \mathrm{C}\right)$ & 15 & 100 & 200 & 300 & 400 & 550 \\
\hline $\begin{array}{l}\text { Heat capacity } \\
\left(\mathrm{J} / \mathrm{g} \cdot{ }^{\circ} \mathrm{C}\right)\end{array}$ & 1.02 & 0.95 & 1.1 & 1.07 & 1.24 & 1.07 \\
$\begin{array}{l}\text { Conductivity } \\
\left(\mathrm{W} / \mathrm{m}^{\circ} \mathrm{C}\right)\end{array}$ & 185.3 & 182.0 & 217.3 & 218.2 & 228.1 & 187.2 \\
$\begin{array}{l}\text { Expansion } \\
\left(10^{-6} /{ }^{\circ} \mathrm{C}\right)\end{array}$ & $*$ & 24.3 & 25.9 & 26.7 & 28.2 & $*$ \\
\hline
\end{tabular}

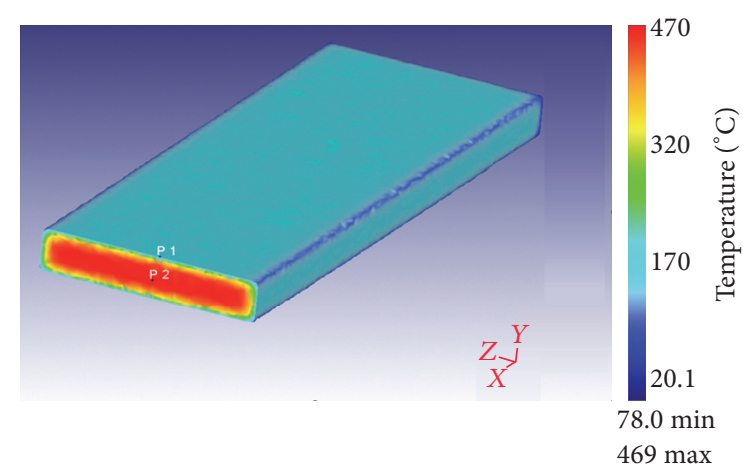

FIGURE 2: Results of temperature after cooling time $10 \mathrm{s.}$

(core) of the block shown in Figure 2 were employed for observing the temperature $(T)$ change with cooling time $(t)$ from $470^{\circ} \mathrm{C}$ to 20 . Figure 3 gives the relative calculated results. The largest temperature difference between points 1 and 2 occurs in range of cooling time 10 to $15 \mathrm{~s}$. The temperature difference produces the thermal stress in the internal, which leads to the deformation of the block. At the same time, the release of phase transition latent heat results in a decrease in the slope of $T$ - $t$ curves. Because the quenching process is very severe, the effect of the phase transition latent heat release on the temperature could be ignored. After quenching for about 350 seconds, the temperature distribution in the block evolves to be uniform and the magnitude is close to the water temperature. With increasing time, the temperature of the two points gradually reduces; it takes about $650 \mathrm{~s}$ for them to be cooled to the target temperature $20^{\circ} \mathrm{C}$.

The final residual stress distribution of quenched block in length direction is shown in Figure 4. Figure 5 gives stress $(X)$-time curves for points 1 (surface) and 2 (core) of the block. In the initial stage of quenching, the normal stress was tensile at the surfaces and compressive in the core. Because of the sudden contraction of the surfaces and the great temperature gradient in the vicinity of the surface, the normal stress at surface point 1 increases sharply to about $70 \mathrm{MPa}$ and then decreases slowly with the decreasing temperature gradient. At the same time, the compressive normal stress at the center point 2 gradually increases. During this process, the block undergoes plastic deformation. The plastic deformation finally results in the fact that the surface tensile residual stress shifts to compressive and the core 


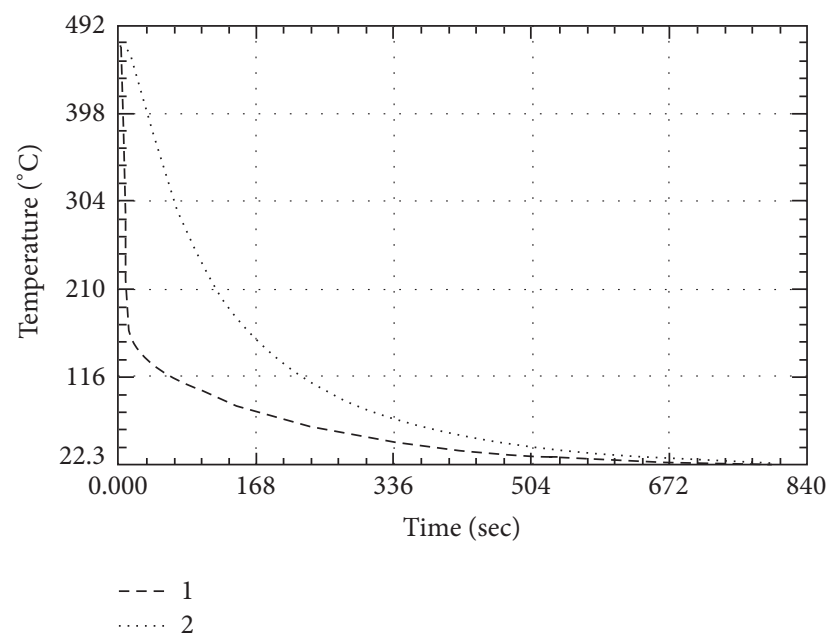

FIgURE 3: Temperature-time curves for points 1 and 2 in Figure 2.

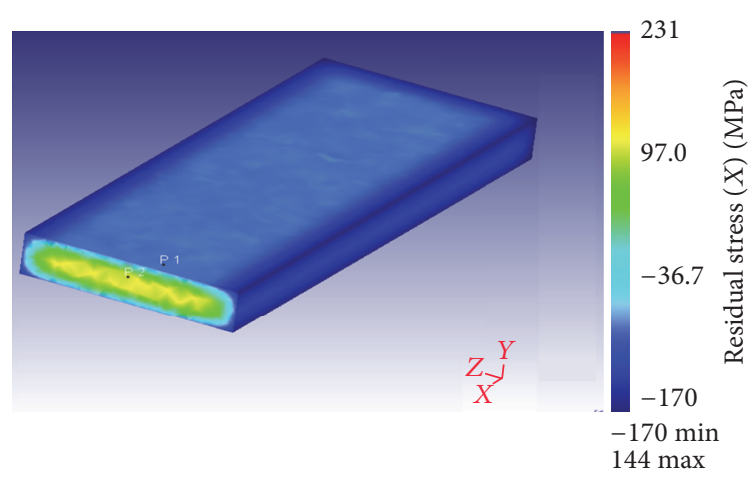

FIgURE 4: Results of residual stress $(X)$ after quenching.

compressive stress switches into tensile stress at the later stage of quenching.

\subsection{Compression Simulation Results and Discussion. Figure 6} shows the simulated results of residual stress distribution of the block for different cold compression values $0 \%, 1 \%$, $2.5 \%, 4 \%$, and $5 \%$. The $x$ - and $y$-axes stand for residual stress value and percentage of the block forging, respectively. It can be seen that the residual stress in length direction ranged from $-170 \mathrm{MPa}$ to $140 \mathrm{MPa}$ when the quenching process was completed (Figure 6(a)). After conducting 1\% cold compression deformation on the block along the direction of highness, the distribution range of residual stress in length direction significantly reduced that ranged from -110 MPa to $120 \mathrm{MPa}$ (Figure 6(b)). This is due to the plastic deformation that redistributed the residual stress of the block. The range of residual stress in length direction of the block sharply reduces to the range from $-65 \mathrm{MPa}$ to $60 \mathrm{MPa}$ as the compression deformation value runs up to $2.5 \%$, and the uniformity was better than before (Figure 6(c)). However, when the deformation continued to come up to $4 \%$ and $5 \%$, the ranges of residual stress in length direction of the block sharply widened which are from $-90 \mathrm{MPa}$ to $100 \mathrm{MPa}$ and from$110 \mathrm{MPa}$ to $120 \mathrm{MPa}$, respectively (Figures 6(d) and 6(e)).
TABLE 3: Cold compression deformation scheme.

\begin{tabular}{lccccc}
\hline Percentage & $1 \%$ & $2 \%$ & $3 \%$ & $4 \%$ & $5 \%$ \\
\hline $\begin{array}{l}\text { Plastic deformation } \\
(\mathrm{mm})\end{array}$ & 0.4 & 0.8 & 1.2 & 1.6 & 2.0 \\
$\begin{array}{l}\text { Experimental } \\
\text { deformation }(\mathrm{mm})\end{array}$ & 0.9 & 1.2 & 1.6 & 2.0 & 2.4 \\
\hline
\end{tabular}

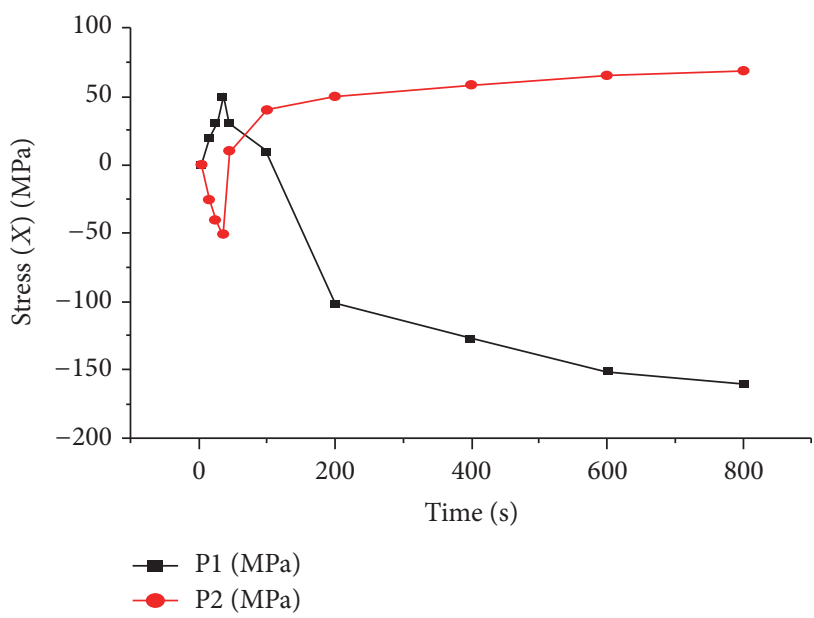

Figure 5: Stress $(X)$-time curves for points 1 and 2 in Figure 4.

This phenomenon can be explained by the fact that if the cold compression deformation continues to increase, it will produce much more elastic deformation in the block which is the main cause of the increase of residual stress. Therefore, for this simulation, it can be concluded that the optimal compression deformation value is about $2.5 \%$ for this largesized block forging.

\section{Cold Compression Experiment}

Figure 7 shows the cold compression experimental specimens of 7A85 aluminum alloy forging with the size of $100(L) \times$ $60(W) \times 40(H) \mathrm{mm}$ provided by Southwest Aluminum Company and equipment of Central South University including X-ray diffraction device, and 4000t CNC hydraulic press machine. The entire experimental course was subdivided into four operations, which are quenching, measuring residual stress for the first time, cold compression deformation along the highness direction of specimens, and measuring residual stress for the second time. $1 \%-5 \%$ cold compression deformation was conducted on the quenched specimens along highness direction, respectively. The data of plastic deformation is shown in Table 3. Compression speed was $0.1 \mathrm{~mm} / \mathrm{s}$, which can be accurately controlled by the hydraulic control system. The residual stress of the same points on the surface of compressed specimens was measured by X-ray diffraction device in $X, Y$, and $Z$ directions.

The results of cold compression deformation experiment are shown in Table 4 and Figure 8 . The average values of residual stress for quenched specimens are $-174.9 \mathrm{MPa}$, 


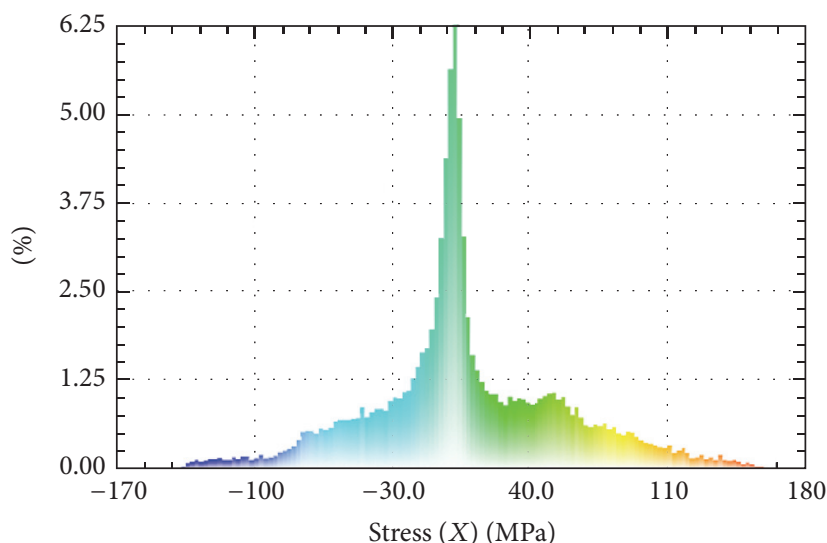

(a)

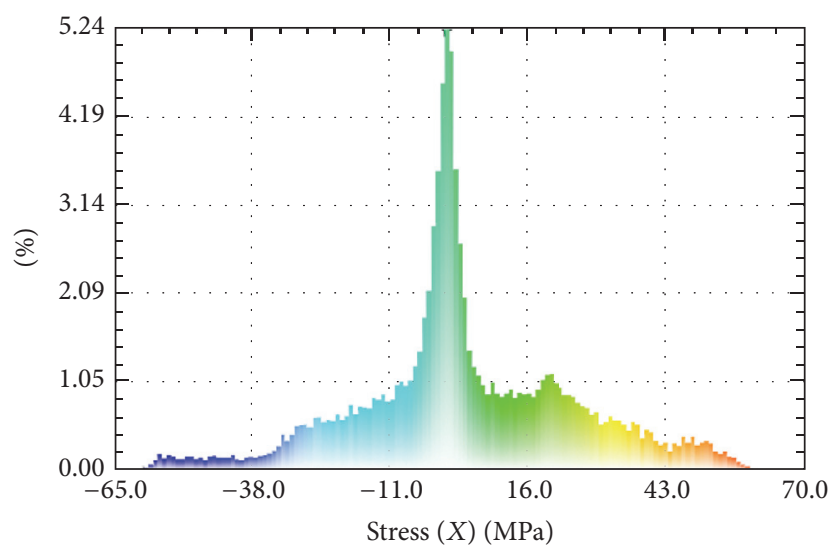

(c)

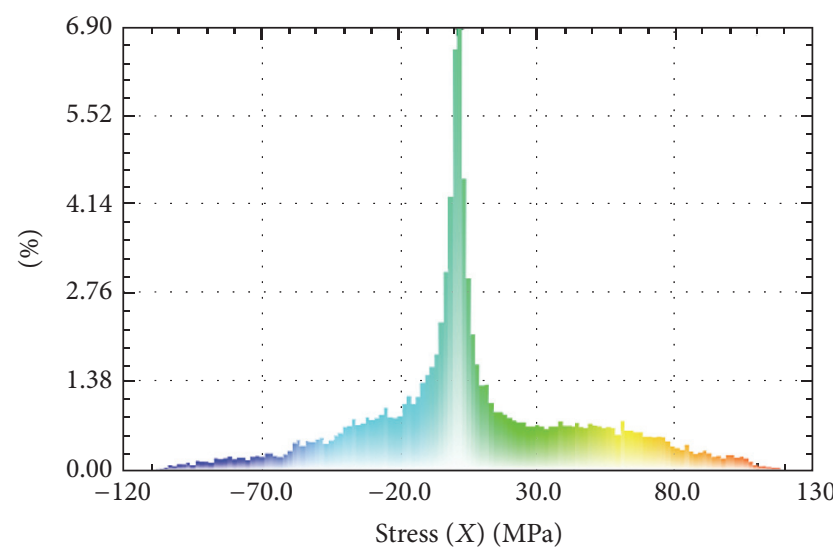

(b)

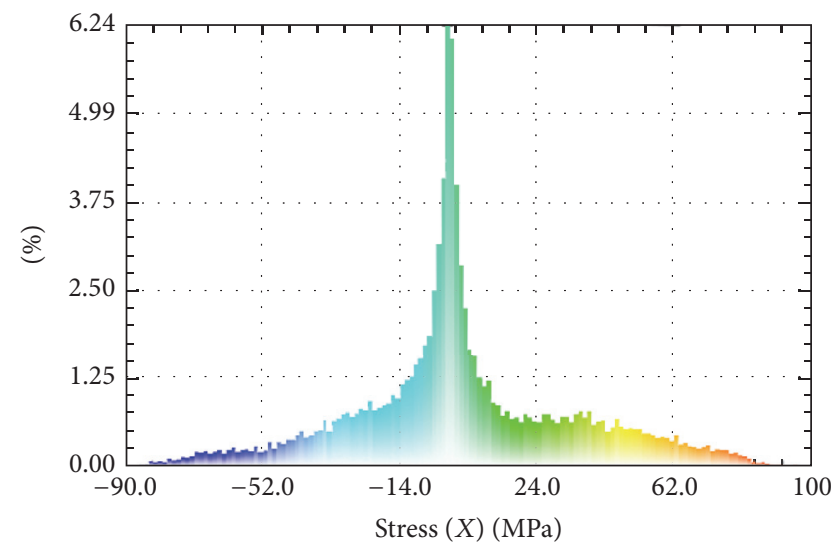

(d)

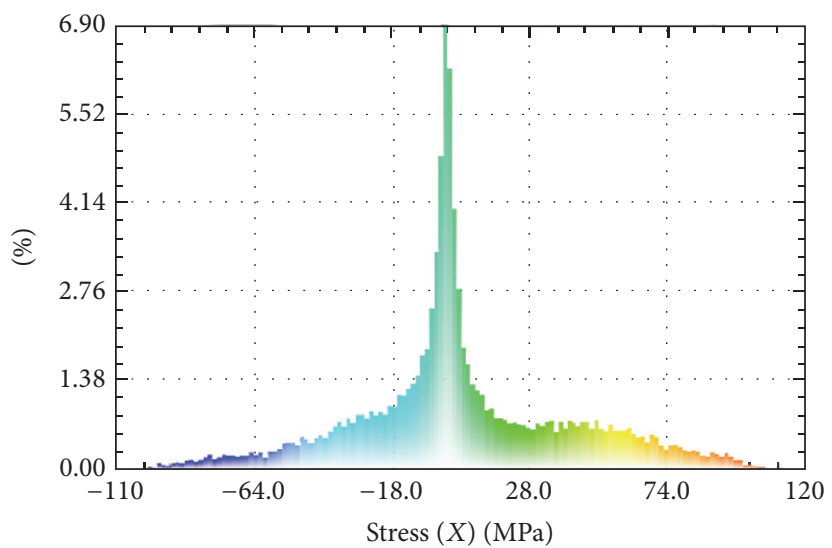

(e)

FIgURE 6: Results of residual stress $(X)$ distribution for different compression value: (a) quenched; (b) 1\%; (c) 2.5\%; (d) 4\%; (e) 5\%.

$-156.7 \mathrm{MPa}$, and $-150.6 \mathrm{MPa}$, in $X, Y$, and $Z$ directions, respectively. After conducting $1 \%$ compression deformation, the values of them reduced to $7 \mathrm{MPa}, 53.4 \mathrm{MPa}$, and $-5.9 \mathrm{MPa}$, respectively. When compression deformation exceeded $2 \%$, the level of residual stress in three directions both obviously increased. It can be concluded that $1 \%-2 \%$ is the optimal compression deformation value which can reduce
$70 \%$ residual stress for these $7 \mathrm{~A} 85$ aluminum alloy specimens sized $100(L) \times 60(W) \times 40(H) \mathrm{mm}$.

\section{Conclusions}

(1) Physical property parameters of 7A85 aluminum alloy such as heat capacity, thermal conductivity, 

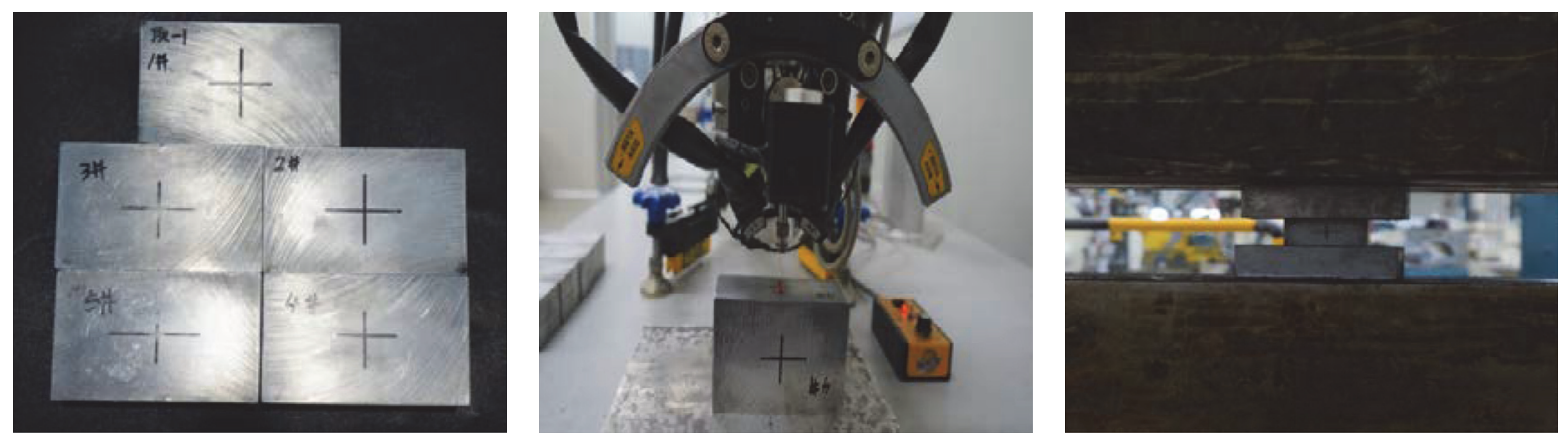

FIGURE 7: Experimental specimens and equipment.

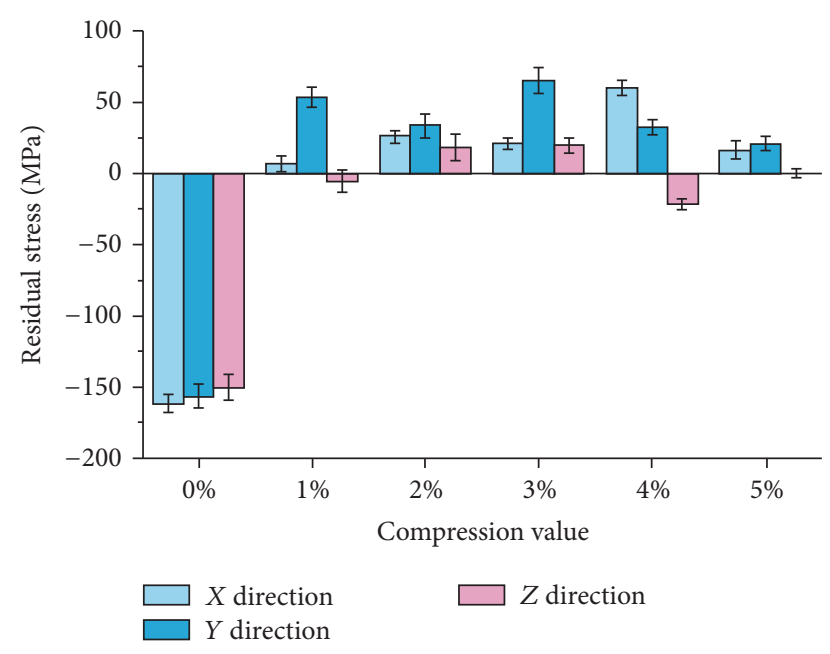

FIGURE 8: The error for measurement data.

TABLE 4: Residual stress of quenched and compressed specimens.

\begin{tabular}{lccc}
\hline $\begin{array}{l}\text { Compression } \\
\text { value }\end{array}$ & $\begin{array}{c}X \text { direction } \\
(\mathrm{MPa})\end{array}$ & $\begin{array}{c}Y \text { direction } \\
(\mathrm{MPa})\end{array}$ & $\begin{array}{c}Z \text { direction } \\
(\mathrm{MPa})\end{array}$ \\
\hline $0 \%$ & -174.9 & -156.7 & -150.6 \\
$1 \%$ & 7.0 & 53.4 & -5.9 \\
$2 \%$ & 28.2 & 33.7 & 18.3 \\
$3 \%$ & 22.4 & 65.3 & 19.1 \\
$4 \%$ & 64.9 & 32.4 & -22 \\
$5 \%$ & 17.8 & 20.8 & -0.1 \\
\hline
\end{tabular}

and expansion coefficient were obtained through experiments, which are the foundation of subsequent simulative and experimental research.

(2) Cold compression deformation method has a significant effect on reducing quenching residual stress if an appropriate amount of compression deformation is chosen. The simulation results show that, in length direction of 7A85 aluminum alloy thick block with a large size of $260 \times 1150 \times 5300 \mathrm{~mm}$, quenching residual stress can be significantly reduced by about $2.5 \%$ cold compression deformation along the direction of highness, with residual stress in length direction ranging from $-65 \mathrm{MPa}$ to $60 \mathrm{MPa}$, compared with that from $-170 \mathrm{MPa}$ to $140 \mathrm{MPa}$ after quenching. The experimental results indicate that the optimal compression deformation value is about $1 \%$ $2 \%$, reducing $70 \%$ residual stress for 7 A85 aluminum alloy specimens sized $100 \times 60 \times 40 \mathrm{~mm}$.

\section{Competing Interests}

The authors declare that they have no competing interests.

\section{Acknowledgments}

The authors would like to thank The State Key Laboratory of High Performance and Complex Manufacturing (zzyjkt201402) and the National Basic Research Program of China (Grant 2012CB619504) for their financial support.

\section{References}

[1] E. A. Starke Jr. and J. T. Staley, "Application of modern aluminum alloys to aircraft," Progress in Aerospace Sciences, vol. 32, no. 2-3, pp. 131-172, 1996.

[2] P. Jeanmart and J. Bouvaist, "Finite element calculation and measurement of thermal stress in quenched plates of high strength 7075 aluminum alloy EJ," Materials Science and Technology, vol. 1, no. 3, p. 765, 1985.

[3] D. J. Smith, C. G. C. Poussard, and M. J. Pavier, "An assessment of the Sachs method for measuring residual stresses in cold worked fastener holes," Journal of Strain Analysis for Engineering Design, vol. 33, no. 4, pp. 263-274, 1998.

[4] M. Koç, J. Culp, and T. Altan, "Prediction of residual stresses in quenched aluminum blocks and their reduction through cold working processes," Journal of Materials Processing Technology, vol. 174, no. 1-3, pp. 342-354, 2006.

[5] H. F. Wang, D. W. Zuo, and L. T. Wang, "Numerical analysis of surface residual stress of NC milling 7075-T7451 aluminum alloy, Key Engineering Materials, vol. 40, no. 7, pp. 718-722, 2009.

[6] A. Arcari, R. De Vita, and N. E. Dowling, "Mean stress relaxation during cyclic straining of high strength aluminum alloys," International Journal of Fatigue, vol. 31, no. 11-12, pp. 1742-1750, 2009. 
[7] H. Gong, Y.-X. Wu, and K. Liao, "Influence of pre-stretching onresidual stress distribution in 7075 aluminum alloy thickplate," Transactions of Materials and Heat Treatment, vol. 30, no. 6, pp. 201-205, 2009.

[8] C.-Y. Yao, Numerical Simulation of Quench Temperature Field and Internal Stress Field of Aluminum Alloy 7050 Thick Plate, Central South University, Changsha, China, 2007.

[9] K. Liao, Y.-X. Wu, H. Gong, and S.-Y. Zhang, "Application of integral method on residual stress calculation along depth in aluminium alloy thick plate," The Chinese Journal of Nonferrous Metals, vol. 19, no. 6, pp. 1006-1011, 2009.

[10] M. B. Prime and M. R. Hill, "Residual stress, stress relief, and inhomogeneity in aluminum plate," Scripta Materialia, vol. 46, no. 1, pp. 77-82, 2002.

[11] M. B. Prime, "Residual stress measurement by successive extension of a slot: the crack compliance method," Applied Mechanics Reviews, vol. 52, no. 2, pp. 75-96, 1999.

[12] K. Muammer, "Prediction of residual stresses in quenched aluminum blocks and their reduction through cold working processes," Journal of Materials Processing Technology, vol. 174, pp. 342-354, 2006.

[13] D. A. Tanner and J. S. Robinson, "Modelling stress reduction techniques of cold compression and stretching in wrought aluminium alloy products," Finite Elements in Analysis and Design, vol. 39, no. 5-6, pp. 369-386, 2003.

[14] S. Wang, Analysis of Quenching Residual Stress and Its Reduction Process of 7A85 Aluminum Alloy Component, Central South University, ChangSha, China, 2011. 

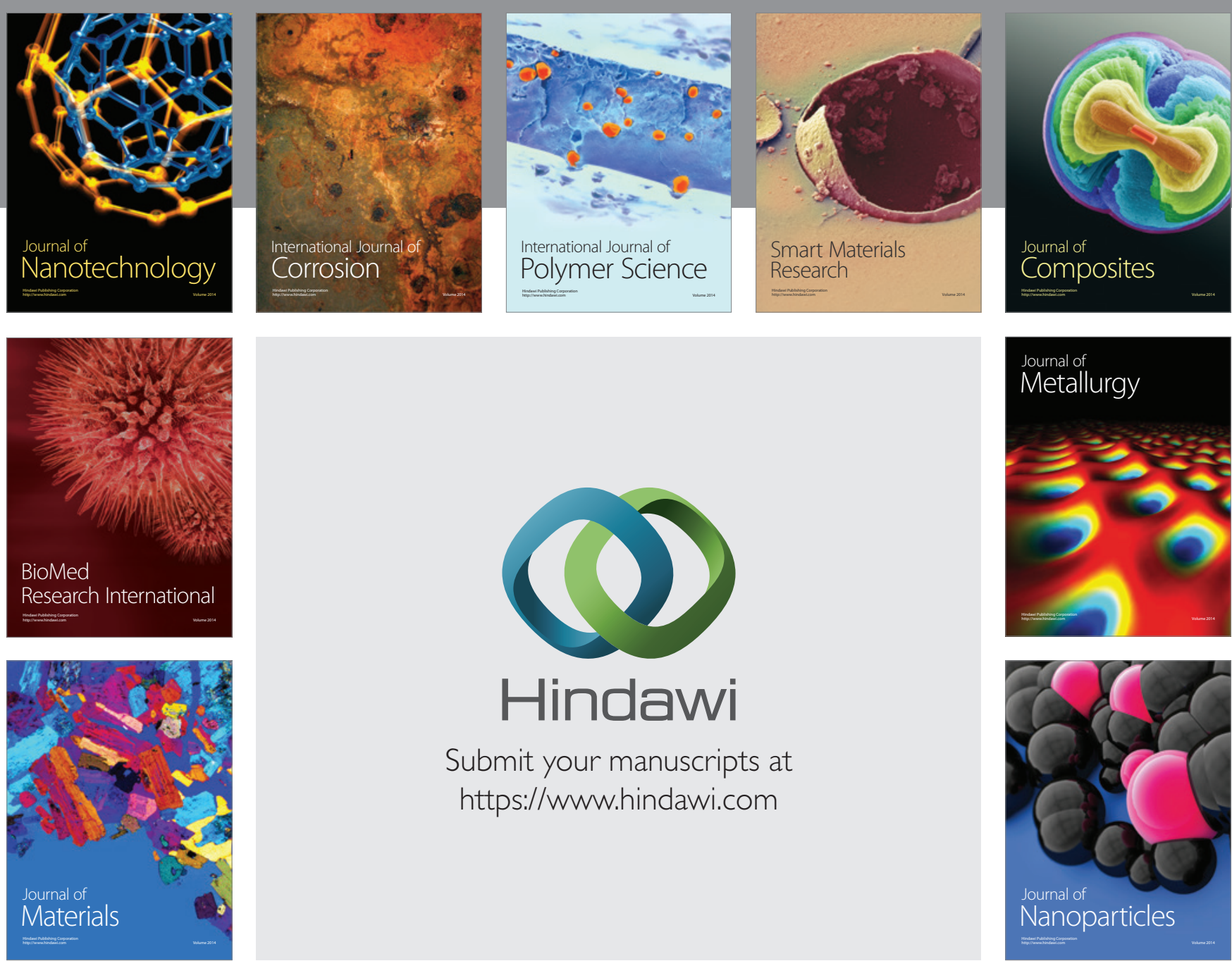

\section{Hindawi}

Submit your manuscripts at

https://www.hindawi.com

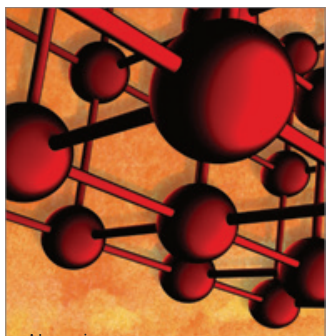

Materials Science and Engineering
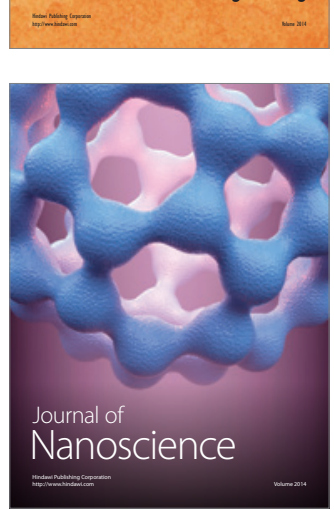
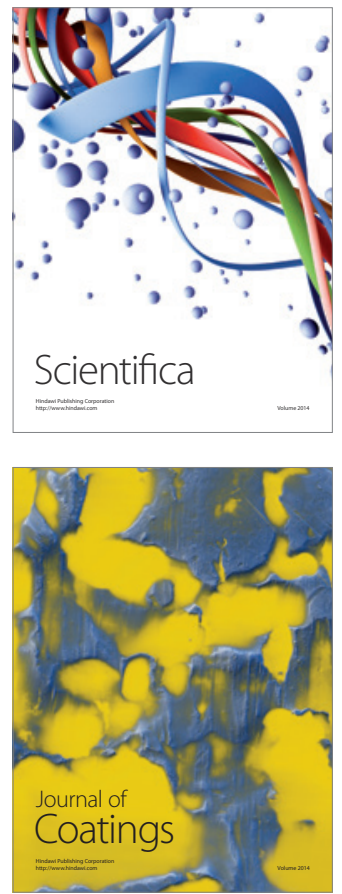
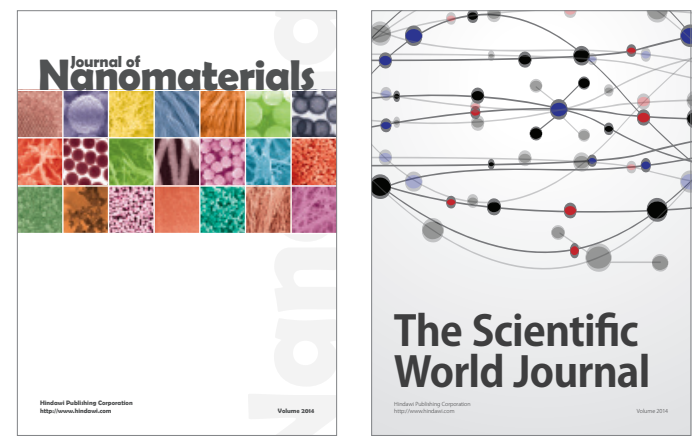

The Scientific World Journal
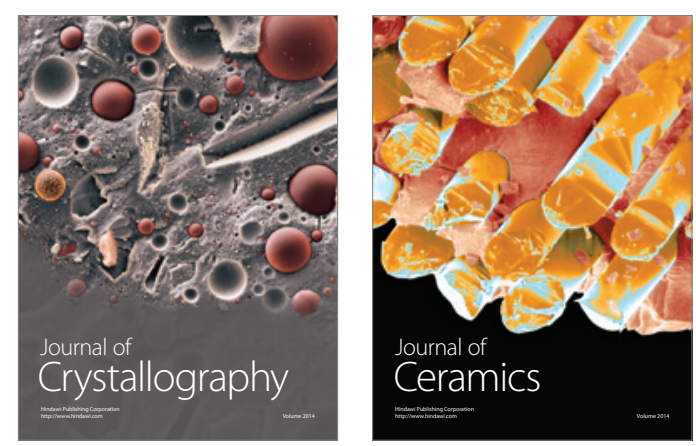
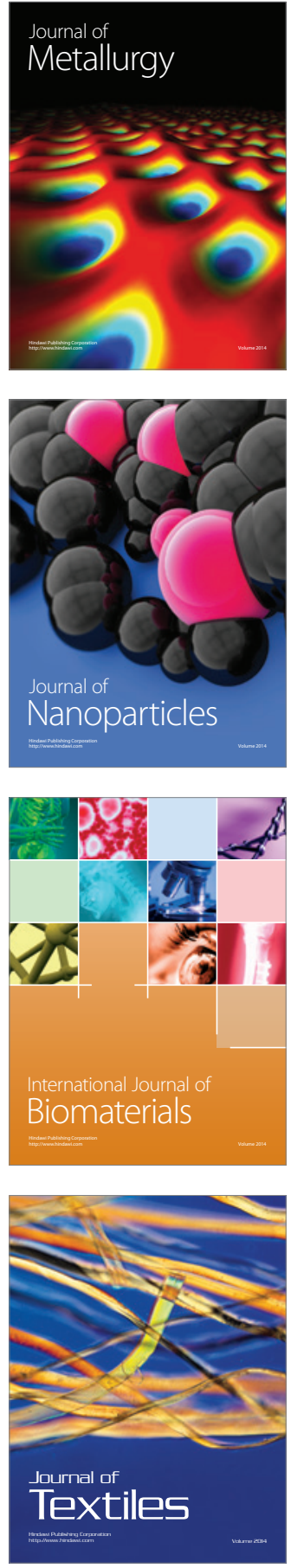